\title{
СОВЕТСКАЯ МОДЕРНИЗАЦИЯ И ГЕНДЕРНЫЕ СДВИГИ В ЧУКОТСКОМ ОБЩЕСТВЕ В СЕРЕДИНЕ ХХ веКа
}

\author{
Л. Н. Хаховская \\ ФГБУН Северо-Восточный комплексный научно-исследовательский институт \\ им. Н. А. Шило ДВО РАН, г. Магадан \\ E-mail: hahovskaya@gmail.com
}

\begin{abstract}
Придерживаясь гендерной и феминистской теории, а также методологии микроистории и истории повседневности, автор анализирует сдвиги в положении женщин-аборигенок на Чукотке в середине XX в. Автор использует архивные документы партийных, советских и хозяйственных учреждений Чукотки. Советская власть активно преобразовывала чукотский традиционный патриархальный уклад. Руководящие работники, как правило, были мужчинами. Поток переселенцев возрастал, и значительный численный перевес среди них также имели мужчины. Поэтому доминировал официальный эмансипирующий мужской взгляд на положение аборигенки, который отрицал ее традиционную роль и облик. Это была внешняя по отношению к аборигенному сообществу власть, обладающая принуждающей силой, имеющая в своем распоряжении значительные средства и ресурсы для проведения социальной инженерии. В советское время аборигенки могли получить сопоставимые с мужчинами возможности по построению карьеры, но этому препятствовала их замкнутость в домашнем укладе. Поэтому в середине XX в. поток социального лифтинга среди женщин был слабым и значительно уступал мужской мобильности. Официальный советский дискурс квалифицировал традиционный чукотский быт как бескультурный и отсталый. Советская власть стремилась к тому, чтобы чукотские женщины коренным образом меняли свой повседневный уклад. Власть и окружающий социум контролировали те действия женщин, которые ранее входили в сферу частной жизни.
\end{abstract}

Ключевые слова: Чукотка, женщины-аборигенки, советизация, модернизация, гендер, феминизм, повседневность, трудовая занятость, частная жизнь.

DOI: $10.34078 / 1814-0998-2019-4-118-125$

\section{ВВЕДЕНИЕ}

В гуманитарных дисциплинах последнего времени влияние и актуальность приобретают исследования, связанные с гендерным подходом и феминистской перспективой. Феминизм как теория, чувствительная к отношениям доминирования / подчиненности, переопределил подход к гендерной истории, которая осмысливается не как «женская» или «мужская», а как история властных отношений (Haraway, 1988; Пушкарева, 2007, 2010; Hawkesworth, Disch, 2016). Taкой подход дает возможность видеть прежде всего действия, направленные на формирование социального порядка, определяющего положение женщин в конкретном сообществе.

В данной статье с гендерных и феминистских позиций предпринят анализ сдвигов в положении аборигенных женщин советизируемой Чу-

(C) Хаховская Л. Н., 2019 котки. Эти сдвиги были особенно выразительны в 1940-1950-х гг., во время массового наступления на традиционный патриархальный уклад. Исследователи многократно отмечали, что советская эмансипация женщин совпадала с общими тенденциями феминистского движения, это была своего рода политика государственного феминизма (Блохина, 2003; Хасбулатова, 2005; Хасбулатова, Смирнова, 2008). При этом гендерные сдвиги на материале советского этапа истории аборигенных сообществ Северо-Востока России изучены совершенно недостаточно. Немногие опубликованные работы (Ломова, 2001; Доржеева, 2009) описывают некоторые аспекты положения аборигенных женщин, но, как правило, обобщенно, по всем коренным народам в целом, что не позволяет увидеть этническую и культурную специфику.

Наше исследование опирается также на методологию микроистории и истории повседневности, которая отмечена вниманием прежде всего к 
локальным сюжетам и микросюжетам, но усматривает за локальными событиями сдвиги макроисторического масштаба (Кром, 2003). В ходе работы проанализирован большой круг архивных источников, отложившихся в результате деятельности партийных, советских и хозяйственных учреждений Чукотки рассматриваемого периода.

Процессы, происходившие в чукотском обществе, можно назвать аборигенным вариантом государственного феминизма. Советская модернизация в области гендерных отношений на Чукотке складывалась таким образом, что обусловила доминирование официального эмансипирующего мужского взгляда на положение аборигенки и отрицание ее традиционной роли и облика. В регионе теперь постоянно присутствовала советская, партийная и хозяйственная администрация, представленная, как правило, мужчинами; рос поток переселенцев, среди которых наблюдался значительный численный перевес в пользу мужчин. Это была внешняя по отношению к аборигенному сообществу власть, обладающая принуждающей силой, имеющая в своем распоряжении значительные средства и ресурсы для проведения социальной инженерии. Общий характер гендерных сдвигов в чукотском обществе состоял в том, что действия женщин, ранее входившие в сферу повседневности и частной жизни, становились все более публичными, общественно востребованными и контролируемыми со стороны власти и окружающего социума.

\section{ПРЕОБРАЗОВАНИЕ ТРАДИЦИОННОЙ ЭКОНОМИКИ И ЖЕНСКИЙ ТРУД}

Основное содержание труда женщин в традиционном чукотском обществе составляли повседневные бытовые обязанности, требовавшие постоянной активности и значительных физических усилий - разделка туш животных, обработка шкур, пошив одежды, приготовление пищи, уход за детьми и домочадцами, установка и разбор яранги, упаковка и распаковка домашнего скарба, сопровождение кочевых караванов (аргишей). Помимо этого, женщины, в особенности молодые, эпизодически участвовали в выпасе оленей и помогали мужчинам-пастухам при особых обстоятельствах - отбивке стада, отеле. Традиционное разделение труда отсекало женщин лишь от охотничьего промысла (морского и наземного), запрещая им даже прикасаться к орудиям и оружию. Эта гендерная сепарация осуществлялась строго и для женщин была преодолима только при демонстративной перемене пола. Такие случаи, хотя и крайне редкие, все же в традиционной культуре признавались легитимными (Богораз, 1934. С. 134, 135).

Советская модернизация, затронувшая все сферы присваивающей экономики, разрушала эти границы, открывая перед женщинами новые горизонты трудовой активности. Их участие во всех видах промыслов (морзверобойный, охотничий, рыболовецкий) было очень желательным для советской власти как в экономическом, так и в социальном аспекте, так как оно восполняло недостаток людской силы, демонстрировало самостоятельность и самодостаточность женщин, их выход за рамки предписываемого традицией поведения. Женщин призывали в массовом порядке становиться не только пастухами, но и охотницами на пушных и морских зверей, мотористами вельботов, что было совершенно недопустимо прежде. Эти призывы находили определенный отклик. Самым экстремальным сдвигом для чукотского сообщества стало участие женщин в морской охоте и их присутствие на байдарах и вельботах. Первоначально такие шокирующие мужчин-зверобоев примеры были единичны. Но политика органов власти достаточно быстро привела к тому, что охота на морских животных перешла в разряд если не привычного, то допустимого поведения женщин. К 1952 г. в Чукотском районе Чукотского национального округа, в котором был наиболее развит морзверобойный промысел, 45 женщин проходили обучение на стрелков и мотористов вельботов [Государственный архив Магаданской области (далее ГАМО), ф. П-22, оп. 1, д. 531, л. 85].

Еще более важным являлся пушной промысел, поскольку его продукция не потреблялась внутри хозяйств, как мясо и жир морских животных, а практически полностью поставлялась государству и была источником валюты. Во время Великой Отечественной войны это существенно помогало фронту, поэтому партия и правительство требовали всемерного развития промысла на местах. На Чукотке за ружья и капканы взялись многие незанятые колхозники, главным образом женщины и подростки. Так, колхоз «Чуванский» (Марковский район) в 1942 г. организовал две женские промысловые бригады [ГАМО, ф. П-28, оп. 8, д. 1, л. 134]. В 1944 г. среди 288 охотников Чаунского района насчитывалось 10 женщин. В пушной добыче отличились чукчанки Памьяна и Рахтына, наряду с мужчинами они были премированы и занесены на Доску почета [ГАМО, ф. П-355, оп. 2, д. 45, л. 25об.].

Эта новая тенденция, сформированная в тяжелые годы, была продолжена, хотя и в меньшем масштабе. В целом ряде чукотских хозяйств имелось несколько профессиональных женщинохотниц, время от времени на промысел выходили и любительницы. Например, в начале зимы 1951 г. в колхозе «Имени Первого мая» (ВосточноТундровский район) для выполнения плана пушных заготовок активистка Мария Дулган мобилизовала 6 женщин, организовала из них бригаду, которая за короткий срок добыла 63 зайца и 34 горностая [ГАМО, ф. П-22, оп. 1, д. 492, л. 25]. Высокие достижения женщин в промысле широко пропагандировались. В конце 1950-х гг. на 
всю страну прогремело имя охотницы-чукчанки Клары Каляны, которая за один сезон добыла 74 песца. За этот рекорд ей присвоили звание Героя Социалистического Труда. Однако характерно, что очень скоро Каляна сменила место работы и стала швеей в мастерской села Конергино (Иультинский район).

Таким образом, участие аборигенных женщин в пушной охоте и тем более в морском промысле все же не было массовым. Более существенно в первые советские десятилетия расширилось участие чукчанок в пастушестве и каюрстве (перевозке грузов на оленьих нартовых упряжках). При этом если ранее этот труд был растворен в повседневном укладе семьи и стойбища, воспринимался как естественный и потому являлся социально «невидимым», то теперь он получал широкую общественную востребованность и признание. Советские преобразования очень скоро начали приводить к нехватке пастухов и каюров во вновь организуемых колхозах и совхозах. Произошло это, во-первых, вследствие вывоза из тундры детей и подростков для обучения в школах, поскольку в традиционном хозяйстве детский и подростковый труд составлял не менее $50 \%$ бюджета времени пастухов [Государственный архив Российской Федерации, ф. А-310, оп. 18 , д. 331 , лл. 103,104 ; д. 420, л. 16]. Вовторых, часть мужчин-пастухов приступила к другим обязанностям (строительство, рыболовство, охота), некоторые из них становились советскими активистами. Наконец, в советское время многократно увеличился поток грузов, а до конца 1960-х гг. преобладали гужевые перевозки.

В поисках выхода советская администрация увидела возможность привлечь к этому труду женщин, действуя методом «кнута и пряника». С одной стороны, женщин принуждали участвовать в колхозной работе и вырабатывать минимум трудодней (100 трудодней в год в 1950-х гг.). С другой стороны, немаловажным стало экономическое и социальное поощрение - женщины получали оплату, возможность самостоятельной покупки продуктов и товаров, их трудовые достижения публично освещались и особо вознаграждались. Такие действия руководящих органов принесли определенный эффект. Так, в Марковском районе в начале 1950-х гг., невзирая на сложные условия труда, перевозками грузов занималось значительное количество женщин: «B аргишах работает большое количество молодых женшин и девушек (30-40 (человек) на аргиш), в течение 1-2 месяцев они не бывают в усадьбе колхоза» [ГАМО, ф. П-22, оП. 1, д. 531, л. 10]; «Зимой более $80 \%$ женшчин работают в транспортных бригадах. Своим практическим трудом они обеспечивают товарами население глубокой тундрыл» [ГАМО, ф. П-28, оп. 1, д. 14, л. 4]. В этом же районе в начале $1950-$ х гг. в оленеводческих бригадах работали 25 женщин-пастухов из общего числа 250 трудоспособных женщинколхозниц, т. е. каждая десятая [Там же, л. 3].

Однако в целом наступивший «дефицит» пастухов и каюров женщины восполнить не смогли, поскольку эта работа отрывала их от семьи на длительный срок и слишком резко меняла привычный, размеренный характер кочевой жизни. Поэтому на постоянной основе в выпасе оленей и сопровождении грузов женщины участвовали лишь определенное время, как правило, до рождения детей, а затем либо возвращались в яранги, либо оседали в стационарных селениях. Последняя тенденция все чаще преобладала над первой. Материалы переписи 1959 г. показывают, что большая часть аборигенок не была связана ни с оленеводством, ни с каюрством - из 3255 трудоспособных женщин пастухами работали 155, возчиками - 4 чел., численность чумработниц не превышала 500 чел. [ГАМО, ф. Р-128, оп. 1, д. 977, лл. 1-55].

«Исходу» чукотских женщин из тундры в значительной мере способствовали совершенно новые для них отношения статусного и структурного неравенства, которые советская власть внесла в микросообщества оленеводов. В советское время подход к повседневному женскому труду в оленеводстве изменился: теперь он признавался профессиональной деятельностью и подлежал оплате. Однако эта прогрессивная инновация носила избирательный характер, она охватила далеко не всех женщин-тундровичек. Новшество заключалось в том, что в штатном расписании оленеводческой бригады появилась трудовая позиция «чумработница», в обязанности которой входило бытовое обслуживание двух-трех пастухов бригады, за что она получала трудодни и соответствующую оплату.

Таким образом, чумработниц было в 2-3 раза меньше, чем пастухов, что приводило к гендерной асимметрии в профессиональном отношении. Другие женщины, также находившиеся в бригадах и заботившиеся о своих мужьях, отцах или братьях, делали то же самое, но ни официального статуса чумработниц, ни оплаты не имели: «Женщины в оленеводческих бригадах работают цельми днями наравне с чумработницами: помогают кочевать, выдельвать мехсырье, шьют меходежду для мужей-пастухов, готовят пищу, раздельвают оленей, вымораживают весь день полог, готовят дрова, а их труд не учитьвается» [ГАМО, ф. П-22, оп. 1, д. 531, л. 1]. В результате в оленеводческом коллективе создавалась конкуренция за оплачиваемые «женские» рабочие места, доступ к ним становился привилегией и зачастую связывался с позицией и влиянием мужчин-пастухов (жена бригадира всегда была чумработницей).

Далее, сам труд чумработниц, который заключался в повседневных бытовых обязанностях и раньше был частным делом семьи, теперь стал объектом внимания органов власти. Оценивая 
содержание и качество этого труда с внешних позиций, наблюдатели как бы давали оценку личности чукотской женщины, характеризовали ее поведение и моральный облик: «Чумработнищьы Наанлина и Мохнаткина проявили большую заботу о своих пастухах, в их бригадах у пастухов всегда сухая и изелая одежда. К возвращчению дежурных пастухов приготовлена горячая пища. Причем заслуга их в том, что они приготовляют разнообразную пищу, а именно: варят суп, кашу, жарят мясо. ... Чумработница Гуванна совершенно безответственно относится к своей работе. Пастухи ее бригады уходят на дежурство в сырой одежде, без горячей пищци. Сама она занимается пьянкой» [Там же, лл. 33-35]. Таким образом, социализация бытовой повседневности оленеводов, ее переход в регулируемые и вознаграждаемые государством трудовые отношения влекли за собой повышение уровня требований, дисциплинирование женщин, возможность применять экономические и общественные меры воздействия на тех, кого считали нерадивыми.

Отношения структурного, экономического, поведенческого (и вытекающей отсюда моральноэтической оценки) неравенства являлись факторами значительного давления на чукотских женщин, побуждали их покидать оленеводческие бригады и переезжать в поселки, тем более, что к этому призывали и органы власти, стремившиеся убрать из тундры «лишних» людей, т. е. реально не участвующих в выпасе. Однако в оседлых поселениях Чукотки сфера официальной женской трудовой занятости в середине $\mathrm{XX}$ в. была узкой и переселявшиеся тундровички зачастую не находили работы. Они опять погружались в повседневный домашний труд, который, в отличие от ситуации в тундре, не получал хотя бы частичного признания в качестве социально востребованной занятости и какой-либо оплаты. Тем не менее сфера повседневности здесь также оказалась объектом советской модернизации и повлекла за собой инновационные требования со стороны власти.

Не стала сколько-нибудь значимым выходом попытка развивать в стационарных селениях Чукотки подсобные скорняжные и пошивочные промыслы, ориентированные именно на официальное трудоустройство женщин. Организация кустарных мастерских (артелей) по выделке шкур и пошиву изделий из кожи и меха стояла на повестке дня с первых лет установления советской власти в регионе - потребность в такой продукции была велика и промыслы могли приносить значительный доход колхозам. Но основным препятствием на этом пути стала организационная и экономическая слабость хозяйств, которые не могли предоставить артелям ни отдельных помещений, ни современных инструментов и инвентаря, не говоря уже о внедрении механизированных способов обработки и пошива. В итоге аборигенки, даже выполняя колхоз- ные задания, продолжали работать на дому вручную, используя примитивные каменные скребки, игольники, наперстки и другие кустарные инструменты. Другой причиной являлось нежелание самих женщин расширять круг своих обязанностей, ведь они должны были обеспечивать меховой одеждой и утварью всех собственных домочадцев, что отнимало много времени и сил. Таким образом, женщины в поселках продолжали шить для своей семьи, а на требования профессионально заняться выделкой и шитьем отвечали, по сути, саботажем.

Существенным сдвигом в восприятии чукотскими женщинами обязанностей хотя и традиционных, но «внешних», не идущих непосредственно из семьи, стала тенденция разделить эти обязанности в зависимости от локализации исполнителей. Поселковые аборигенки старались отказаться от наиболее трудоемкой и «грязной» работы по выделке шкур, выдвигая требование присылать их из тундры уже обработанными [ГАМО, ф. П-28, оп. 1, д. 58, л. 14]. Другими словами, они хотели бы переложить эту часть работы на плечи тундровичек, оставив себе только кройку и шитье. Дополнительной мотивацией для оседлых жительниц служило то обстоятельство, что расценки за пошивочную и скорняжную работу существенно различались в пользу первой и не соответствовали трудовым затратам. Так, за пошив меховой кухлянки, на который требовался один день, в 1957 г. женщинам начисляли 2.5 трудодня, а за выделку шкуры взрослого оленя, которая велась в течение 2-3 дней, всего 0.75 трудодня [ГАМО, ф. П-28, оп. 5, д. 2, л. 21]. В целом же оплата и за выделку, и за пошив была низкой и не могла служить значимым экономическим стимулом для привлечения аборигенок.

Постепенно женщины-аборигенки в стационарных селениях начали занимать трудовые позиции, не связанные с традиционной экономикой. Для некоторых из них не требовалось особой подготовки, так как это была обслуживающая занятость в советских организациях, хозяйствах и на предприятиях - санитарки, няни, уборщицы, повара, швеи. Часть аборигенок, получивших специальные навыки и умения в образовательных учреждениях (школа колхозных кадров, педагогическое училище и др.), работали учетчиками, кассирами, счетоводами. Важной стороной социальной модернизации и гендерных сдвигов в чукотском обществе становилось вовлечение женщин в гражданский активизм и призыв их во властные структуры.

Однако в целом в середине XX в. в органах власти местные женщины были представлены очень скромно и гораздо менее пропорционально, нежели приезжие, с которыми в этот период они не могли конкурировать из-за недостаточного уровня образования и социальной мотивированности. Действительно, в Чукотском округе на 
начало 1950 г. из 97 женщин, работавших на руководящей работе, только 26 были аборигенками [ГАМО, ф. П-22, оп. 1, д. 368, л. 42]. Согласно переписи 1959 г., лишь 32 женщины-аборигенки занимали руководящие должности низового уровня (председатели сельсоветов, директора небольших предприятий). Их доля в общей численности трудоспособных женщин не достигала и $1 \%$ [ГАМО, ф. Р-128, оп. 1, д. 977, лл. 1-55].

Особое место в социальной сфере занимала деятельность женщин-аборигенок во вновь организованных «сверху» женских советах (женсоветах). Этот институт, созданный в стране под эгидой партийных органов в первые годы советской власти, на Чукотке появился только в конце 1940-х гг., но развивался активно: к началу 1950-х гг. женсоветы были созданы в 55 колхозах, женотделы - во всех районах и округе. Руководителями женсоветов на всех иерархических ступенях, от села до округа, назначались аборигенки-активистки. От женсоветов ожидали существенной помощи в реорганизации все еще «отсталого», по мнению советских работников, общественного уклада. В их компетенцию входила борьба не только за трудовую вовлеченность женщин, но и за соответствие их облика и быта общесоветским стандартам.

В целом извне прививаемый чукотскому обществу взгляд на существенно расширившееся участие женщин в общественном труде не встречал, судя по всему, принципиальных несогласий со стороны аборигенов. Определенную роль в разрушении структурных стереотипов, безусловно, сыграла присущая традиционному чукотскому обществу известная самостоятельность аборигенок. Как в свое время отметил В. Г. Богораз, у чукчей женщина достаточно часто имела собственный голос и участвовала в принятии решений (Богораз, 1934. С. 100, 101). В советское время аборигенки могли получить сопоставимые с мужчинами возможности по построению собственной карьеры, но на первых порах этому препятствовала их замкнутость в домашнем укладе. Поэтому в середине XX в. поток социального лифтинга среди женщин был слабым и значительно уступал мужской мобильности. Для сравнения, согласно переписи 1959 г., руководящие должности разного уровня занимали 85 мужчин-аборигенов, что составляло $2.7 \%$ от общего количества трудоспособных мужчин [ГАМО, ф. Р-128, оп. 1, д. 977, лл. 1-55]. Существенный перелом в этой тенденции произошел лишь на рубеже 1960-1970-х гг.

\section{РЕГУЛИРОВАНИЕ ПОВСЕДНЕВНОЙ ЖИЗНИ}

Официальный советский дискурс квалифицировал традиционный чукотский быт как «бескультурный» и «отсталый». Критике подвергались практически все аспекты домашней жизни и повседневного поведения, включая материаль- ность - предметы, вещи и способы обращения с ними. В вопросах преобразования быта власть в первую очередь апеллировала именно к женщинам, считая их ответственными за эту сферу частной жизни. Чукотским женщинам предписывалось содержать в чистоте свои жилища, готовить разнообразную пищу, правильно ухаживать за детьми, переходить с традиционной одежды на европейское платье. Борьба за советский быт стояла в одном ряду с политической эмансипацией женщин: окружной партийный комитет в конце 1920-х - начале 1930-х гг. нацеливал партийные и советские организации на работу среди «туземок» по таким направлениям, как «вовлечение в сочстрочтельство и поднятие культурного уровня; улучшение бытовых условий; улучшение материального положения; борьба за освобождение женщины-националки» [ГАМО, ф. П-22, оп. 1, д. 3, л. 155].

В первое время основной упор был сделан на агитационной и просветительской работе. При медпунктах, кооперативах, школах и Красных ярангах создавались уголки матери и ребенка, оснащенные красочными плакатами с демонстрацией надлежащих культурных образов. Среди женщин организовывали беседы в доступном изложении на широкий круг тем, связанных с эмансипацией и «европеизацией» (о сущности советской власти, о правах женщин, о религиозно-бытовых пережитках, об уходе за телом, о правильном питании и др.). Но подобные мероприятия приносили мало эффекта, традиционная повседневность слабо поддавалась преобразованиям.

К середине 1940-х гг. главной мишенью наступления на традиционность стало чукотское жилище - яранга, как переносная (у оленеводов), так и стационарная (в береговых селениях). Господствовала внешняя точка зрения, что «существующая чукотская жилая яранга находится в полном противоречии с сочиалистической реконструкцией чукотского хозяйства, являясь большим тормозом в культурно-бытовом развитии коренного населения»; а проживающие в ней «влачат свою жизнь в дыме, сырости, холоде и темноте» [ГАМО, ф. П-22, оп. 1, д. 180, л. 47; д. 188, л. 80].

Однако, поскольку было ясно, что глобальная цель - полный отказ от яранг - пока недостижима, власти шли на паллиативные решения. Аборигенам настойчиво предписывалось «принять меры по наведению чистоты в ярангах» [ГАМО, ф. П-12, оп. 1, д. 77, л. 72]. Советские работники всячески приветствовали формирующееся у чукчей-активистов стремление жить по-европейски, преобразовывать свое жилище и даже ставили их в пример своим товарищам: «Имеются отдельные яранги (Гемауге, Чайвыргина, Тенетегреу, Рультуги), у которых можно поучиться содержанию и чистоте квартир руководящим работникам райцентра. Населе- 
ние требует улучшения и обстановки в яранге. Лучший охотник селения Раупелян Ринтуги просит оказать ему помощзь в приобретении мебели: стол, стулья, зеркало и др.» [ГАМО, ф. П-12, оп. 1, д. 71, л. 25].

Женская инициатива эдесь приветствовалась особо, так как свидетельствовала о прогрессивных тенденциях в этой считавшейся наиболее консервативной части чукотского общества. Действительно, как ни парадоксально, в вопросе жилищных преобразований гораздо более активными были мужчины, а не женщины. Среди последних с такого рода инновациями выступали лишь отдельные молодые представительницы крайне немногочисленной интеллигенции: «В селе Инчоун местный педагог Дина Павловна Тутыне, 1925 года рождения, в 1946 г. окончила педучилище в Анадыре. Полог превратила в настоямую комнату: деревянные стены, деревянный пол, окно, и уже поставлена мебель, кровать, стол» [ГАМО, ф. П-22, оп. 1, д. 636, л. 8].

Для того, чтобы побудить основную массу чукотских женщин проводить в ярангах хотя бы повседневную уборку, органам власти необходимо было изменить оптику восприятия действительности самими женщинами, заставить их увидеть то состояние, которое официально квалифицировалось как «грязь». С этой целью женсоветы организовывали в поселках специальные бытовые комиссии, члены которых устраивали подворный обход с последующим публичным вынесением оценок, поощрением победителей и критикой нерадивых. Именно эта публичность была призвана прививать чукотским женщинам новые вкусы, новую эстетику, которые должны были стать нормой.

В ходе проверок выяснилось, что наиболее грязные яранги были у тех, кто в них выделывал шкуры, что становилось для женщин весомым аргументом в пользу работы вне дома или даже полного отказа от выделки и перехода на европейскую одежду. Вообще «вхождение» контролирующих инстанций в яранги повлекло за собой распространение надзора на такие ежедневные процессы, тесно связанные с физиологией и телесностью, как ношение одежды и питание.

Важным аспектом советского дисциплинирования чукотских женщин стало предписание обрести надлежащий внешний вид: «... сами женшины не умываются и не умьвают своих детей, до сих пор в своих ярангах ходят совсем голье, хотя у них есть полная возможность приобрести верхнюю одежду и нательное бельё» [ГАМО, ф. П-22, оп. 1, д. 531, л. 12]. Те же санитарнобытовые комиссии, которые проверяли чистоту жилищ, должны были обучать женщин правилам личной гигиены, побуждать их носить предметы интимного гардероба. К началу 1950-х гг. успехи в этом были достаточно скромны. Так, секретарь райкома ВКП(б) Восточно-Тундровского района, чукчанка Тынна на слете активисток в январе 1952 г. сообщала: «Женшины стали значительно чище содержать яранги, мыть посуду, ежедневно стали умываться и умывать своих детей, некоторые из них начали носить нательное белье» [ГАМО, ф. П-22, оп. 1, д. 492, л. 19]. Актуальность этого вопроса для органов власти демонстрируется тем, что он обсуждался на самом высоком уровне - например, на окружной партийной конференции многих руководящих работников критиковали, так как они «не добились того, чтобь все женщины носили нательное белье под меходеждой» [ГАМО, ф. П-22, оп. 1, д. 531, лл. 63, 64].

Далее, органы власти констатировали серьезные недостатки в рационе местных жителей, способах приготовления пищи и сопутствующих действиях: «...питание коренного населения абсолютно нерационально построено, преимущественно употребляется пища однообразная $u$ чаще всего в замороженном виде и употребляется много крепкого чая. Как правило, пищза не готовится. Очень медленно идет употребление в пищу других продуктов (кроме хлеба) - крупь, соли и т. д. Посуда не разделена на грязную и чистую. Не моются сырые продукты - мясо» [ГАМО, ф. П-22, оп. 1, д. 636, л. 10]. Для изменения положения в этой сфере более эффективным оказался не индивидуальный патронаж, как в случае с жилищами, а массовое, коллективное вовлечение в новые практики.

Так, в 1955 г. в селе Чаплино (Чукотский район) с помощью членов выездной медицинской комиссии и женщин из числа приезжих (учителя, работники полярной станции, жены офицеров) был организован «...вечер питания, где приготовлена выставка разных блюд - 5 столов, 1 cупь, 2 - вторые блюда, 3 - стол закусок, 4 мучные блюда, 5 - стол прикорма грудных детей. Все было приготовлено из продуктов, имеющихся в магазинах. У каждого стола, кроме ответственного за стол, дежурила женшина местного населения. После рассказов и объяснений в две смень по 45 человек в помещуении избы-читальни накормили (всех) обедом из разнообразных блюд... В помещении был установлен большой сколоченный из досок стол. При электрическом освещении, под звуки радио проходил этот своеобразный банкет. Затем заслушали доклад о разнообразном и рациональном питании, была выпущена стенная газета и фотомонтаж, в заключение был проведен концерт самодеятельности с выступлением местных женшин с местными танцами и до 2-х часов ночи танцевали» [Там же, л. 11].

В селе Лорино (Чукотский район) с инициативой привить аборигенам новые пищевые привычки выступила учительница местной школы, в центре ее внимания оказались уже не оседлые жители, а оленеводы. Она «в воскресенье на ль- 
жах со стариими школьниками отправилась в ближайшую оленеводческую бригаду (колхоза им. Ленина), захватив с собой продукты, крупьл, сушеные овощи и ... (они) сварили (там) обед, навели чистоту» [Там же, л. 12].

«Поворот» к европейской модели поведения в быту, включавший освоение новых вещей, перемену рутинных привычек и новый взгляд на сферу повседневности, в чукотском обществе в середине XX в. происходил медленно и неравномерно. Активисты и выдвиженцы из аборигенов, стремившиеся во всем подражать коллегам из числа приезжего населения, охотно принимали инновации, считая их обязательными атрибутами своего нового положения. Так, член окружного партийного комитета ВКП(б) чукча Таю выразил убеждение, что с изменением статуса должна меняться и окружающая повседневная обстановка: «Выдвигая националов на работу, нужно их обеспечить квартирами и улучшить ux быт» [ГАМО, ф. П-22, оп. 1, д. 20, л. 32]. Однако, как уже отмечалось, численность женщинактивисток была невелика, поэтому важным путем внедрения нового быта стало следование женщин за их мужьями-активистами. Таким образом, на женщин начала оказывать давление не только советская администрация, но и собственная этническая среда. Этот процесс, как свидетельствуют документы, порой был болезненным и конфликтным.

Так, партийная организация Восточно-Тундровского районного комитета ВКП(б) в 1945 г. разбирала персональное дело чукчи Канта Григория Ефимовича, 1924 г. р., секретаря райкома комсомола. Кант охарактеризован как способный работник, хороший организатор, но имеющий серьезные неурядицы в семье на почве бытовых проблем: «... с семьей у Канта плохо, не все он разумно устраивает, например, нехорошо, что он дерётся с женой и бъёт ребенка, но нужно учесть то, что жена совершенно не хочет заниматься семьей. Посуду приходится мыть самому, а также стирать белье» [ГАМО, ф. П-39, оп. 4, д. 11, л. 33об.]. Сам Кант видел причину именно в сопротивлении жены принять новый домашний уклад: «Дома у меня не все в порядке. Иногда бывают ссоры, а иной раз и драка. Дело в том, что моя жена очень отсталая и не желает устроить культурно наш дом» [Там же, л. 33]. В 1953 г. коммуниста Амтынаквургина, заведующего избойчитальней в селе Ваеги (Марковский район), обвиняли в том, что его жена «до сих пор ходит в оленьих шкурах» и «не переодета в европейскую одежду» [ГАМО, ф. П-28, оп. 1, д. 27, л. 51].

Говоря обобщенно, усилия советской власти по приобщению чукотских женщин к европейской культуре, преобразованию их быта, поведения и сознания в середине XX в. давали пробуксовку. Для аборигенного сообщества это были навязанные, привнесенные подходы и практики, а не внутриэтнические процессы. Но, раз начавшись, эти давления вызывали подвижки социального и ментального характера. В целом советская социальная модернизация в середине XX в. характеризовалась тем, что многие грани частной жизни переставали оставаться таковыми: повседневные процессы теперь должны были идти «на свету» пристального общественного внимания.

\section{ЗАКЛЮЧЕНИЕ}

Политика советской власти по отношению к коренным женщинам была феминистская по содержанию, при этом она порождала неоднозначные последствия. С одной стороны, она была направлена на эмансипацию женщин во всех сферах общественной жизни. С другой - увеличивалась нагрузка, ложившаяся на их плечи, поскольку женщин нацеливали на «мужские» занятия при сохранении и даже расширении всего спектра обязанностей по ведению дома. Советская гендерная модель, реализованная на Чукотке, подразумевала существенное возрастание женской трудовой активности - они шли на «производство», участвовали в общественной жизни, налаживали новый советский быт. Увеличение загруженности сопровождалось изменением качества занятости в сторону повышения публичности и ужесточения индивидуальной ответственности. Многие составляющие женского труда перестали быть частным делом семьи или микролокального сообщества (стойбище, поселение) и связывались теперь с широким общественным и государственным контекстом.

Советская власть руководствовалась либеральными и демократическими ориентирами, направляя усилия на освобождение женщин от патриархальных уз, просвещение и солидаризацию, их равноправие с мужчинами. Одновременно советский строй делал упор на моральной ответственности женщин уже в рамках нового общественного уклада. В результате в социуме формировались переходные позиции и состояния с разными возможностями и неодинаковым положением женщин и мужчин, что порождало внутренние социальные микроконфликты.

\section{ЛИТЕРАТУРА}

Блохина H. A. Понятие гендера: становление, основные концепции и представления // Летняя школа «Общество и гендер»: сайт. 2003. URL: http://www. gender-cent.ryazan.ru/blohina.htm (дата обращения 15.10.2018)

Богораз В. Г. Чукчи. Л.: Изд-во Ин-та Народов Севера, 1934. $192 \mathrm{c}$.

Доржеева В. В. Женщины северной цивилизации. Магадан : Изд-во СВГУ, 2009. 261 с.

Кром М. М. Повседневность как предмет исторического исследования // История повседневности : сб. науч. работ. СПб.: Европейский ун-т в СанктПетербурге, 2003. С. 7-14. 
Ломова Т. Е. «Женский вопрос» на Дальнем Востоке (1917-1927 гг.) : сб. / IV Дальневост. конф. молодых историков. Владивосток, 2001. С. 156-165.

Пушкарева Н. Л. Гендерная теория и историческое знание. СПб. : Алетейя, 2007. 495 с.

Пушкарева Н. Л. Женская и гендерная история: итоги и перспективы развития в России // Историческая психология и социология истории. 2010. № 2. C. 51-64.

Хасбулатова О. А. Российская гендерная политика в XX столетии: мифы и реалии. Иваново : Иван. гос. ун-т, 2005. 372 c.
Хасбулатова О. А., Смирнова А. В. Эволюция государственной политики в отношении семьи в России в XX - начале XXI в.: (историко-социологический анализ) // Женщина в российском обществе. 2008. № 3. C. $3-14$.

Haraway D. Situated knowledges: The science question in feminism and the privilege of partial perspective // Feminist Studies. 1988. Vol. 14, No. 3. P. 575-599.

Hawkesworth M., Disch L. Feminist theory: Transforming the known world // The Oxford Handbook of Feminist Theory. Oxford : Oxford University Press, 2016. P. 1-15.

Поступила в редакичюю 23.04.2019 2.

Поступила после доработки 16.05.2019 2.

\title{
SOVIET MODERNIZATION AND GENDER SHIFTS IN THE CHUKCHI COMMUNITY IN THE MIDDLE OF THE TWENTIETH CENTURY
}

\begin{abstract}
L. N. Khakhovskaya
North-East Interdisciplinary Scientific Research Institute n. a. N. A. Shilo, FEB RAS, Magadan

Following the gender and the feminist theory, as well as the methodology of microhistory and the history of daily routine, the author analyzes the changes in the position of indigenous women in Chukotka in the middle of the twentieth century. The author uses archival documents of the Communist party, Soviets, and economic institutions of Chukotka. The Soviet government was energetically transforming the traditional patriarchal mode of life of the Chukchi people. As a rule, the executives were men. The influx of immigrants was increasing, and the majority of the latter was men, as well. Therefore, dominating was the official emancipating masculine view of the indigenous women position, which denied their traditional role and outlook. In relation to the aboriginal community, this power was external, possessing coercive force as well as considerable funds and resources for social engineering. In the Soviet time, indigenous women could obtain career opportunities comparable to those for men but were incapable of realizing them being exclusively involved with the home. Therefore, the flow of social lifting of indigenous women was weak and significantly inferior to male mobility. The official Soviet discourse qualified the traditional Chukchi mode of life as uncultured and backward. The Soviet government wished for Chukchi women that they radically transform their everyday routine. The Soviet power and the surrounding society controlled the actions of women which had previously referred to their private lives.
\end{abstract}

Keywords: Chukotka, indigenous women, sovietization, modernization, gender, feminism, everyday routine, employment, private life.

\section{REFERENCES}

Blokhina, N. A., 2003, Concept of Gender: Formation, Basic Concepts and Ideas, Summer School "Society and Gender”, http://www.gender-cent.ryazan.ru/blohina.htm (accessed 15.10.2018) [In Russian].

Bogoraz, V. G., 1934, Chukchi, Leningrad, Institut Narodov Severa [In Russian].

Dorzheeva, V. V., 2009, Women of the Northern Civilization, Magadan, North-East State University [In Russian].

Haraway, D., 1988, Situated Knowledges : The Science Question in Feminism and the Privilege of Partial Perspective, Feminist Studies, 14, 3, 575-599.

Hawkesworth, M.; Disch, L., 2016, Feminist Theory: Transforming the Known World, The Oxford Handbook of Feminist Theory, Oxford University Press, 1-15.

Khasbulatova, O. A., 2005, Russian Gender Policy in the XX Century: Myths and Realities, Ivanovo, Ivanovo State University [In Russian].
Khasbulatova, O. A.; Smirnova, A. V., 2008, Evolution of the State Family Policy in Russia in the XX - Early XXI Century: Historical and Sociological Analysis, Woman in Russian Society, 3, 3-14 [In Russian].

Krom, M. M., 2003, Everyday Routine as a Subject of Historical Research, History of Everyday Life : Collection of Rersearch Papers. St. Petersburg, European University at St. Petersburg, 7-14 [In Russian].

Lomova, T. E., 2001, "The Woman Question" in the Far East, 1917-1927, IV Far East Conference of Young Historians, Reports and Abstracts, Vladivostok, 156165 [In Russian].

Pushkareva, N. L., 2007, Gender Theory and Historical Knowledge, St. Petersburg, Aletheia [In Russian].

Pushkareva, N. L., 2010, Women and Gender History: Results and Prospects for Development in Russia, Historical Psychology and Sociology, 2, 51-64 [In Russian]. 